\title{
Boys, blogs and books
}

\section{Margo Pickworth}

3 Bullawai Place, Beecroft, NSW, 2119 Email mpickowrth@ shore.nsw.edu.au

\begin{abstract}
In an action research project, young male students from Sydney, Australia and Richmond, USA contributed to a collaborative writing blog. Both groups of students shared the same text with their class teachers, while using the medium of collaborative blogging, a process which was facilitated and managed by the teacherlibrarian. Data was gathered using both qualitative and quantitative methods to determine whether the project assisted boys to become powerful, prolific and confident writers. Results indicated that the blogging process failed to provide any increase in the volume of writing; however the opportunity to share opinions and ideas globally provided motivation to write more powerfully and with increased confidence.
\end{abstract}

\section{Introduction}

This action research project, carried out under the umbrella of the International Boys' Schools Coalition, sought to answer the following question: How does a collaborative writing project using blogs, help boys to become powerful, prolific and confident writers?

With the advent of Web 2.0 technology, new opportunities have emerged to provide audiences for writing. The blog or weblog is one such tool. Richardson (2009) defines the blog as an "easily created, easily updateable website that allows an author to publish instantly to the internet from any Internet connection" (p. 17). Blogs are not static, but a collection of reflections and conversations that are regularly updated. They engage readers with ideas, questions and links, asking readers to think, respond and interact.

Davis (2009) incorporated blogs into a writing program and found that students communicated more powerfully when they began to 'realise they had an audience who cared about what they had to say'. Further, Ellison and $\mathrm{Yu}$ (2008) found that collaborative blogs assisted class members to help each other understand class concepts. Bacheneimer and Marciano (cited in Ramaswami, 2008) incorporated blogging into their teaching program and found that it had noticeable benefits including making writing more precise, exact and focused. Because of the wider audience it afforded, blogging provided "a more instructive format - for others to read, not just for the teacher's eyes" (Ramaswami, 2008).

This action research project hoped to build on these findings by providing opportunities for writing to a global audience, through a collaborative blog. More precisely, it was hoped to examine whether the introduction of the collaborative blog would assist boys to become powerful, prolific and confident writers. In this context, powerful writing is characterized by relevance, meaning and logic. Prolific writing refers to the amount of text that a writer produces, notably that the writing is substantial and lengthy. Thirdly, confident writing refers to writing in which students feel they can express their personal responses to key ideas

\section{Research context}

The research took place at Shore Preparatory School, situated in a central city location in North Sydney. The research sample comprised twenty-five Year 6 boys (aged 11 and 12 years) from the Preparatory School. Twenty-six students from St Christopher's School, Richmond, Virginia, USA also participated in the blogging process

The research was led by the teacher-librarian, Mrs Margo Pickworth, with the cooperation and assistance of the Year 6 classroom teacher.

\section{Research methodology}

An action research framework was selected. As defined by Stringer (2008), "Action research is a process of systematic inquiry. Its purpose is to provide educational practitioners with new knowledge and 
understanding, enabling them to improve educational practice or resolve significant problems in the classrooms and schools" (p. 13). Action research was a most suitable methodology choice as this study was undertaken in the work context by professional classroom teachers who are active learners themselves and interested in implementing best practice pedagogy with their students.

\section{Research Methods}

Stringer's (2008) Action Research Cycle has been used as a basis for the research method. This involves five broad recurring stages: (1) Designing the study by carefully refining the issue to be investigated; (2) Gathering data from a variety of sources; (3) Analysing data to identify key features of the issue investigated; (4) Communicating outcomes to the relevant audience and (5) Taking action by using the outcomes of the study to work towards a resolution of the issue investigated. As action research is cyclical in nature, a return to the Design Phase, using the new findings, would then follow.

\section{The intervention}

Three blogs were set up to facilitate and maximise the opportunities for writing, identified as Downriver, Downriver A and Downriver B. The blogs integrated the mutual sharing between schools of the text Downriver by Will Hobbs. Several lessons were also implemented to discuss ideas such as themes, setting, plot and characters in the novel. Guidance was also provided on the etiquette and expectations of blogging.

\section{Data collection}

Pre-intervention data was collected through face-to-face interviews with participating students and staff. This was complemented by online surveys, requesting data on attitudes to writing, the amount and type of preferred writing and the perceived ideal conditions for writing. This data was collected to provide some comparison information both before and after the intervention as well as assisting to shape the intervention process itself. I also kept a diary throughout the process to record relevant observations and noteworthy information from a teacher's viewpoint.

Blog posts were regularly submitted by the teacher-librarian and were based on aspects of the novel including characterisation, plot, points of interest in the setting of the novel and relevance to local and personal circumstances. Boys were then encouraged to respond voluntarily to each blog post by adding their own blog comments. They were also encouraged to add blog comments on other students' blog comments. This process continued regularly for six weeks, after which the blogging was reluctantly drawn to a close and the data interpretation process begun.

Data during and after the intervention was collected through

- Face-to-face interviews - Pre- and post- interviews were held with all participants and staff. Students were interviewed in groups of four and staff interviewed individually. A Zoom Recorder tool which collects data in $\mathrm{mp} 3$ format was used to record responses to three interview questions. This enabled me to listen, transcribe into written format and then codify the responses. The interviews used open-ended questions to allow the participants to share attitudes towards writing both before and after the blogging. In particular, the post-interview allowed an opportunity for participants to reflect on their writing process - the best part of the blogging, the effect that the technology had on their writing and the opportunity to collaborate.

- Online surveys - Pre- and post-surveys were undertaken by both participants and staff. The online tool Survey Monkey was used to construct the surveys which consisted of six multiple choice items. The pre-survey gathered baseline data from students on their preferred types of writing, the amount of writing they usually produced and their feelings towards writing. It also asked for which factors could assist their writing and a preference for possible writing audiences.

The aim of the post-survey was to examine the effects of blogging on boys' writing confidence, the amount of writing produced, and the opportunity for meaningful writing by providing a real audience 
with which to share ideas (powerful writing). The Survey Monkey tool provided both a numeric and percentage score for each item on the questionnaire which provided data for analysis.

- Rubric analysis of blog comments: Quantitative analysis of the student's written contribution to the blogs themselves (Blog comments) was analysed using a self-devised rubric tool. The rubric was based on Arnold's (1987) assessment tools used in a longitudinal study of writing abilities. All blog comments were rated $1-4$ according the following six criteria:

- Prolific writers - How often did they contribute to the blog? How long were their replies?

- Powerful writers - Did students provide meaningful, logical and relevant writing in blog entries?

- Confident writers - Did students express personal responses to the key ideas in the blog?

- Engaged writers - Were students able to produce an adequate standard of writing?

- Audience aware writers - Were students aware of the audience with whom they were blogging?

- Collaborative writers- Were students able to link with the ideas of others?

\section{Data Analysis}

A combination of qualitative and quantitative data analysis techniques were used in this action research project. Three broad steps were followed: organisation, description, then interpretation of the data. To protect anonymity during the analysis procedure, all participants were referred to using only their first name. Writing samples from both Shore and St Christopher's were combined for rubric analysis.

Initially, all interview responses were transcribed into Word documents, examined closely, then codified using broad similarities noted in responses. Responses from the pre and post questionnaires were closely examined. The online survey tool provided percentages and numeric analysis of each response. Other comments provided by both staff and students were also considered closely and codified if necessary.

For each of the six writing dimensions, (Prolific, Powerful, Confident, Engaged, Audience aware and Collaborative writing) each piece of student writing was assigned a rating. Following this, the frequency was calculated numerically into tables. Excel charts were constructed for the specific measures of Prolific, Powerful and Confident writing. From the tables and charts, trends could be clearly visible for analysis and interpretation.

Reliability in this research was sought by employing a range of data collection techniques. Validity and authenticity was sought through the honest and accurate reporting of findings. All data collected was kept systematically in digital and paper format, clearly labelled in folders and directly matched with the original questions. All attempts were made to ensure that the research process was transparent both to its participants and the IBSC team.

\section{Results}

Post-blog interviews indicated that the best (most enjoyable) part of the blog was the collaborative aspect. Most students included responses such as 'I enjoyed just writing to see each other's opinions' (Michael) and 'I enjoyed communicating with the boys in the US' (Jack). Other enjoyable aspects were the content of the blog such as the discussion on dangerous animals and football, and the mechanical aspects of blogging such as its ease of use.

When asked about the influence of technology on writing, most students agreed that the blog had influenced the mechanics of their writing. Sample responses included that 'I wanted the boys in the US to see that I am well organised with my punctuation' (Andrew) and the technology 'made me check that my writing was good before I sent it off' (Sam) or 'because there was no spell-check on it so you had to learn it by yourself' (Ed). Most responses displayed an awareness of the need to write well for their audience by using the appropriate mechanics of writing.

(C) 2010 IASL, SLAQ and therein by the authors. Diversity Challenge Resilience: School Libraries in Action Proceedings of the $12^{\text {th }}$ Biennial School Library Association of Queensland, the $39^{\text {th }}$ International Association of School Librarianship Annual Conference incorporating the $14^{\text {th }}$ International Forum on Research in School Librarianship, Brisbane QLD Australia, 27 September - 1 October 2010. 
A third post-blog interview question asked students to consider the influence of sharing with regard to their writing. Some responses indicated writing improved because they enjoyed the content of the blog such as the opportunity to discuss dangerous animals. Most responses however indicated that their writing improved because 'we got to see the opinions of other people' (Hugh); 'I had to make sure that it was making sense because I didn't know who I was blogging with and what they thought'(Lachlan). Only a small number of responses indicated that the sharing had no effect.

In the post-blog student survey questions were designed to investigate whether students had noted any changes in their attitudes to writing, the amount of writing produced, as well as any changes in writing confidence during the blogging process.

The most enjoyable aspect of the collaborative blog appeared to be the reading of others' comments and the least favourable was the writing of their own blog comments. Another significant finding was that most students reported feeling confident about their writing during the blogging process. Twenty-one of twentyfive participants indicated that they felt 'Confident - I felt I had something important to say'.

The majority of students failed to report any difference in the amount of writing they did as a result of the blog. It appears that that their attitude to writing had also remained the same, with half reporting they would like to do it again and half not interested. When asked for future blogging suggestions, the opportunity to 'chat' on free choices of topic was suggested, as well as the opportunity to share an Australian novel, allowing more time and the addition of 'games' to the blog.

Analysis of blog comments revealed a variety of trends. For Prolific Writing, twelve students contributed regularly with blog comments of at least four sentences (Rating of 4). However, fifteen students contributed some blog comments of less than 3 sentences (Rating of 2). This provides a mixed and inconclusive result for this dimension (See table below).

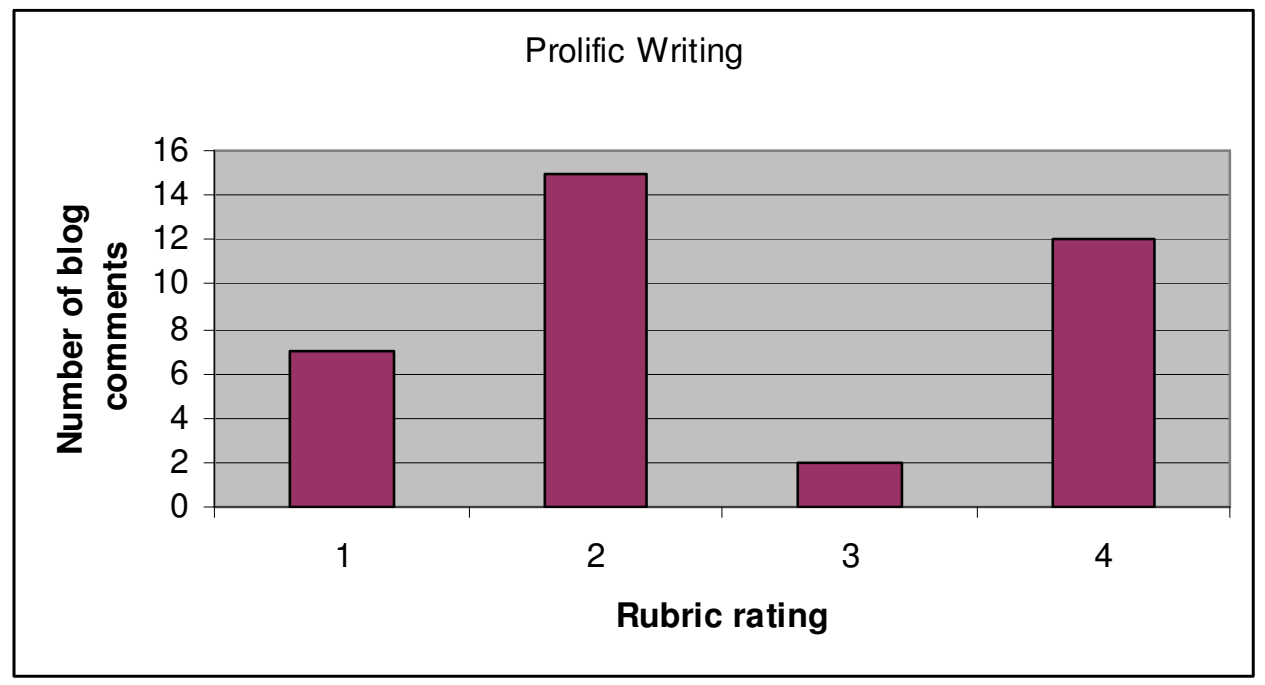

Figure 1. Graph showing ratings of blog comments for Prolific Writing

For Powerful Writing, defined as providing 'meaningful, logical and relevant writing in blog entries', twenty-three responses rated 3 or above: that is, their blog comments included many references to issues raised through blog posts, reading and class discussions. As Figure 2 reveals, only a very small number of responses failed to demonstrate any evidence of powerful writing. 


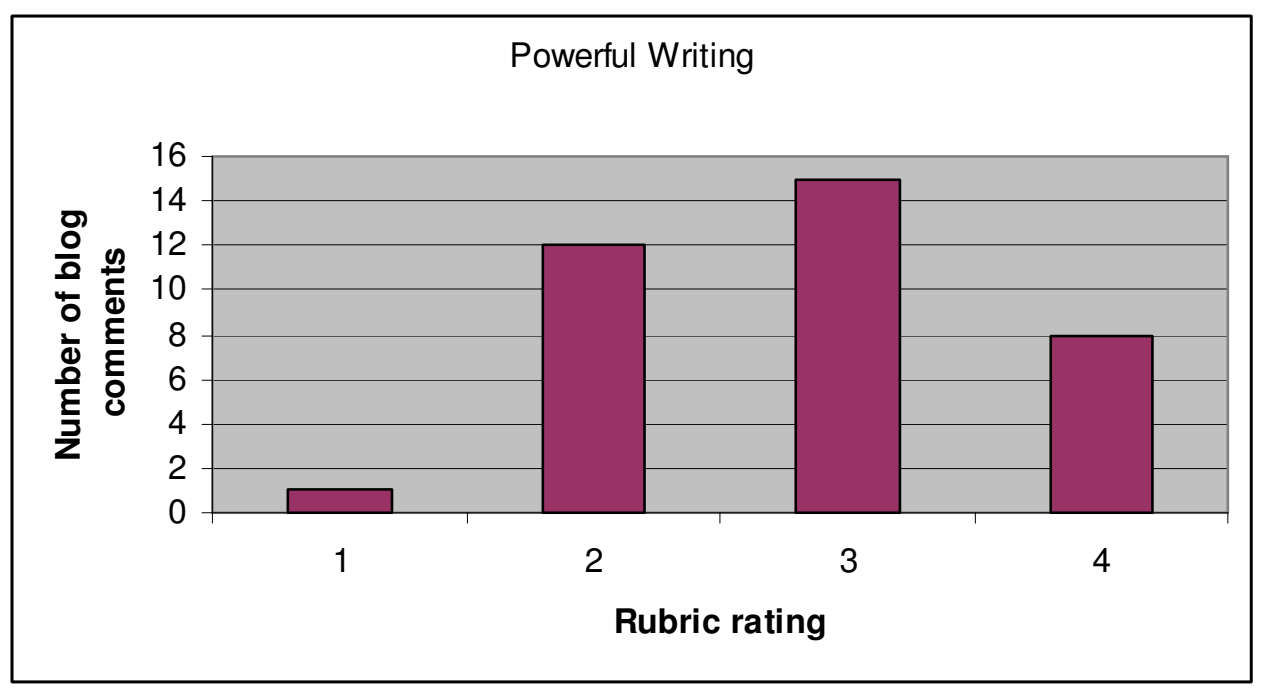

Figure 2. Graph showing ratings of blog comments for Powerful Writing

One of the most significant results was that over half of the blog comments displayed confidence by showing 'Some evidence of personal response to issues raised through blog posts, reading and class discussions'. (Blog comment rubric 3). Only a very small number of blog comments failed to demonstrate any evidence of confident writing.

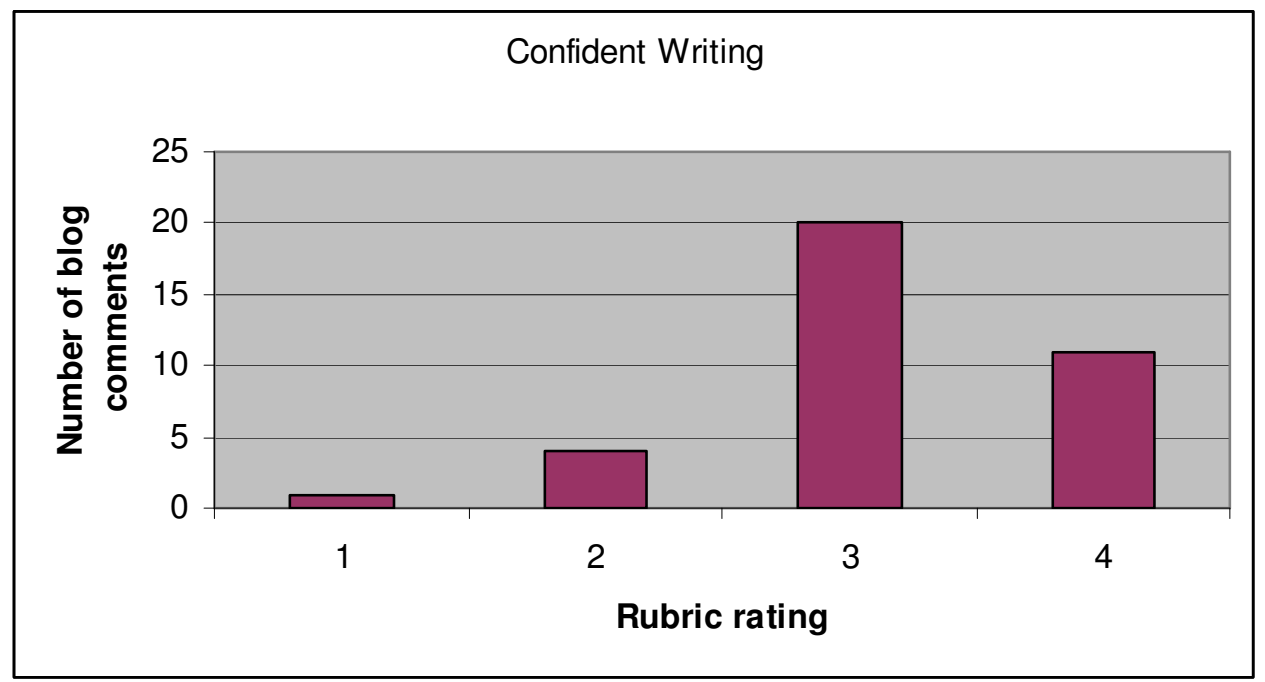

Figure 3. Graph showing ratings of blog comments for Confident Writing

The two dimensions of Engaged Writing and Audience Aware Writing displayed similar trends. The majority of responses rated 3: that is, 'Good standard of spelling, grammar and syntax and making sense with ideas' for Engaged Writing and 'Sound understanding of setting of context and explicit references to audience' for Audience Aware writing.

Evidence of Collaborative Writing, measured by linkages with others ideas, appeared to be limited. Max (St Christopher's) provided an example of collaborative writing by addressing Duncan (Shore) 'I truly appreciate your recommendations and will read the latter of the books you have chosen' (Max 12/2/09 11.39 Downriver B).

In summary, rubric results indicated inconclusive evidence that the collaborative blog contributed to Prolific Writing. On the other hand, there was evidence of both Powerful and Confident Writing, within the definitions used for this action research project. It also appears that the blog allowed opportunities for Engaged and Audience Aware Writing, but there was little evidence of Collaborative Writing.

(C) 2010 IASL, SLAQ and therein by the authors. Diversity Challenge Resilience: School Libraries in Action Proceedings of the $12^{\text {th }}$ Biennial School Library Association of Queensland, the $39^{\text {th }}$ International Association of School Librarianship Annual Conference incorporating the $14^{\text {th }}$ International Forum on Research in School Librarianship, Brisbane QLD Australia, 27 September - 1 October 2010. 
Teacher observations and surveys indicated a positive response to the collaborative blog. Initial comments indicated that this group of boys were reluctant writers and often 'require substantial scaffolding to achieve success - especially with more advanced text types' (pre-blog teacher online survey). At the conclusion of the blog, the classroom teacher expressed disappointment at the quantity of writing but the quality was 'generally pleasing' and 'improved throughout the process' (post-blog teacher online survey). A final positive comment from the classroom teacher revealed that having an 'authentic audience had a tremendous influence to the boys' approach to their writing' (post-blog teacher online survey).

\section{Conclusion}

It is difficult to provide a simplistic answer to my original research question - How does the introduction of a collaborative writing project using blogs, help boys to become powerful, prolific and confident writers? However it was clear that participating in a collaborative blog provided boys with an opportunity to experience a genuine audience for their writing. This is clear from both post-survey and post-interview student responses as well as teacher response.

Over fifty boys contributed regular pieces of writing to the collaborative blogs based on the Downriver novel over a period of six weeks. That is, they continually made thoughtful, meaningful comments to a global cyber audience across the other side of the world. Despite the fact that most students reported that the blog did not make a difference to the amount of their writing, a finding supported also by the analysis of their blog comments, it is concluded that the blogging experience provided opportunities for some powerful, and confident writing to a real audience.

When reflecting on the teaching pedagogy of blogging, it is clear there are several changes needed to our traditional teaching role. Initial guidance on appropriate blog use and blog safety was provided for this project; however the teaching role then became one of connector, not just evaluator. Much of the students' thinking and writing was taking place outside the classroom where the teacher was no longer present. Students could add their comments at a place and time suited to them, rather than being confined to the classroom. This was particularly noticeable with the two different time-zones. Time management became an essential skill for the facilitator as the load of continually checking and managing the blogs was huge.

The simplicity and ease of writing and publishing to a worldwide audience is rapidly expanding with extensive Web 2.0 technology. One of the values of this action research project is that now my findings can be used to begin confidently using such tools effectively in our teaching environments. As expressed by the classroom teacher involved in the project: 'This was a very worthwhile activity which gave me good guidance as to how I could utilise this technology to improve student writing'. I believe that one of the values of my action research project lies right there!

Finally, the teacher-librarian can play an important part in adopting new Web 2.0 technologies. In this project, combining literature with technology provided a perfect opportunity to combine the two essential aspects of our current role in schools. Leadership in such innovative and exciting research projects increases credibility and respect for our profession and I am grateful to the IBSC for their support.

\section{Three key learnings}

- Although collaborative blogging in this context failed to show an increase in the amount of writing, it provided a valuable opportunity for powerful and confident writing for a real audience.

- Using Web 2.0 technology such as blogging requires some re-consideration of our pedagogical role as teachers, but can also provide an opportunity for teacher-librarians to work collaboratively with classroom teachers

- Collaborative blogging, especially with a global audience, can develop a range of literacy skills and provide an enjoyable and challenging learning experience for young male students 


\section{References}

Arnold, R. (1991). Writing development. Buckingham: Open University Press.

Davis, A.(2009). The write weblog bloggers. Edublog insights. Retrieved June 16, 2009, from http://anne.teacheme.com/the-write-weblog-bloggers

Ellison, N.B. \& Wu, Y. B. (2008). Blogging in the classroom: a preliminary exploration of student attitudes and impact on comprehension. Journal of Educational Multimedia and Hypermedia, 17(1), 99-122.

Mertler, C. A. (2009). Action research. Newbury Park, CA: Sage Publications.

Midgette, E., Haria, P., \& MacArthur, C. (2008, February 1). The effects of content and audience awareness goals for revision on the persuasive essays of Fifth- and Eighth-Grade students. Reading and Writing: An Interdisciplinary Journal, 21(131-151). (ERIC Document Reproduction Service No. EJ785479). Retrieved August 29, 2009, from ERIC database.

Mills, G. E. (2007). Action research: A guide for the teacher researcher, Upper Saddle River, NJ: Pearson Education.

Paquette, J. (1981, January 1). The influence of sense of audience on the writing processes of eight adolescent boys. (ERIC Document Reproduction Service No. ED218606). Retrieved August 29, 2009, from ERIC database.

Ramaswami, R. (2008). The prose (and a few cons, too) of blogging. The Journal, 35(11), 21-25.

Richardson, W. (2006). Blogs, wikis and podcasts. Thousand Oaks, CA: Corwin Press. .

Richardson, W. (2009). Blogging. Retrieved June 10, 2009, from http://weblogged.com/category/blogging/

Stringer, E. (2008). Action research in education. Upper Saddle River, NJ: Pearson Education. 